\title{
The Effect of Electron Irradiation on Polybutene-1 and Its Ethylene Copolymers
}

\author{
M. Hribova*, F. Rybnikar And D. Manas \\ Department of Production Engineering, Tomas Bata University in Zlin, 760 01, Czech Republic \\ The beta irradiation, as one of several possibilities how to modify the polymer properties resulted in isotactic \\ polybutene-1 (PB-1) and its random copolymers with ethylene (E) mainly in chain scission without chain \\ cross-linking. The original phase I did not change by irradiation, only the transformation rate of phase II to I \\ increased with the irradiation dose and ethylene groups in PB-1/E copolymers. Beta irradiation decreased the \\ sample crystallinity, crystal size, and perfection.
}

PACS: 61.82.Pv, 61.25.hp, 82.35.Jk

\section{Introduction}

Isotactic polybutene-1 (PB-1) belongs to commercial polyolefines. Compared to other polyolefines, it has good mechanical properties such as high creep and tear resistance, toughness, strength, low stiffness, good impact and abrasion resistance and excellent elastic recovery. It is resistant to many chemicals, environmental stress cracking and high temperatures. The advantage represents easy processing and recycling. PB-1 is a typical partially crystalline polymorphous polyolefine with helical conformation crystallising in four different crystal forms (I, II, III). The unstable form II transforms spontaneously within several days at room temperature to the stable form I.

The remarkable properties are affected by a slow phase II $\rightarrow$ I transformation rate, because phase I has improved properties in respect of phase II.

There were many attempts to increase the II $\rightarrow$ I transformation rate in $\mathrm{PB}-1$ :

1. Application of various nucleation agents or solid crystal additives was an obvious choice, because recrystallization is a phase transition process involving nucleation. The attempts were only partially successful [1] instead of primary crystallization where addition of artificial nucleating agents is a common practice.

2. The effect of basic physical parameters is very important. The transition rate reaches its maximum at $25^{\circ} \mathrm{C}$, which is a very high super-cooling $\left(\approx 100^{\circ} \mathrm{C}\right)$. Such super-cooling is in primary melt crystallization typical for homogeneous nucleation process. From the practical point of view the relatively low transformation temperature is welcome, but the transformation rate is too slow. Increasing or decreasing sample temperature re-

\footnotetext{
* corresponding author; e-mail: mhribova@ft.utb.cz
}

sults in decreasing transformation rate. The increasing pressure or tensile deformation has a positive effect on the transformation rate [2] but ultrasound treatment had no effect [1].

3. The increased transformation rate was also found in some PB-1 copolymers, mainly copolymers with ethylene [3]. The drawback may represent inferior mechanical properties.

4. The electron and gamma irradiation of PB-1 results mainly in chain scission [4], the effect on II $\rightarrow$ I transition is not reported uniformly [5]. Irradiation in air produced radicals which were scavenged by oxygen and this prevented crosslinking.

In comparison with other linear polyolefines there are some open questions concerning PB-1 structure, crystallization and mainly II $\rightarrow$ I recrystallization. The isothermal crystallization by cooling melt takes place in the usual way through heterogeneous nucleation and spherulite growth similar as e.g. in linear polyethylene (LPE), isotactic polypropylene (iPP), poly-4-methylpentene-1.

Here we report results of irradiation effects concerning the structure and transformation rate of PB-1 and some PB-1/PE copolymers.

\section{Experimental}

For measurements two PB-1 homopolymers with different molecular weight (melt flow index) and 4 random PB-1/ethylene copolymers differing in molecular weight and ethylene content (Table I) were used. The basic structural sample characteristics are summarized in Table I.

The methods used for structure, morphology and properties characterization are described elsewhere [6]. 
Sample material characterictics of PB-1 and its copolymers.

TABLE I

\begin{tabular}{|c|c|c|c|c|c|c|}
\hline $\begin{array}{l}\text { Sample } \\
\text { labeling }\end{array}$ & $\begin{array}{l}\text { Density } \\
{\left[\mathrm{g} / \mathrm{cm}^{3}\right]}\end{array}$ & $\begin{array}{c}T_{\mathrm{m}} \\
{\left[{ }^{\circ} \mathrm{C}\right]} \\
\end{array}$ & $\begin{array}{l}\text { MFI }[\mathrm{g} / 10 \mathrm{~min} \text {, } \\
\left.190^{\circ} \mathrm{C} / 2.16 \mathrm{~kg}\right]\end{array}$ & $\begin{array}{l}\text { MFI }[\mathrm{g} / 10 \mathrm{~min}, \\
\left.190^{\circ} \mathrm{C} / 10 \mathrm{~kg}\right]\end{array}$ & Composition & $\begin{array}{c}\% \\
\mathrm{PE}\end{array}$ \\
\hline 110 & 0.914 & 117 & 0.4 & 13 & PB-1 homopolymer & 0 \\
\hline 300 & 0.915 & 116 & 4 & 70 & PB-1 homopolymer & 0 \\
\hline 9217 & 0.899 & 103 & 2.5 & 46 & experimental PB-1/ethylene copolymer & 12 \\
\hline 8640 & 0.906 & 97 & 1 & 28 & random PB-1/ethylene copolymer & \\
\hline 8340 & 0.911 & 97 & 4 & 100 & random PB-1/ethylene copolymer & \\
\hline 8510 & 0.897 & 81 & 10 & & random high PB-1/ethylene copolymer & 41 \\
\hline
\end{tabular}

$T_{\mathrm{m}}$ - melting temperature, MFI - melt flow index characterizing molecular weight [7],

\% PE - measured by FTIR analysis [6].

\section{Results and discussion}

Wide angle X-ray scattering (WAXS) analysis yielded basic structure characterization. All samples crystallized immediately after melting in form II and during 18 days completely transformed to form I, also the copolymers. No separate polyethylene peaks were found in the X-ray scans of copolymers which confirm that the ethylene segments are randomly situated in the copolymer chain. The $\mathrm{X}$-ray scans measured for identical initial phase II and transformed phase I disclosed the following results: The sample crystallinity $(X)$ decreased from 67 to $45 \%$ due to increased ethylene content in the copolymer and the irradiation dose. The crystal size $L_{110}$ calculated from (110) diffraction peak width [8] decreased in a similar way from about 720 to $370 \AA$. The crystal size of the final phase I was about $1.5 \%$ lower than the parent phase II which proves that the phase I is closely connected with parent phase II. The irradiation effect was responsible for decrease of $12 \%$ in crystallinity and of $23 \%$ crystal size values. The situation in copolymers was analogous taking into account the reduced amount of $\mathrm{PB}-1$ in the copolymer.

X-ray measurements of phase II content at various time interval during cooling at room temperature allowed to determine the II $\rightarrow$ I transformation rate and its half-time $(r)$ as shown in Table II. Sample beta irradiation by the dose up to $198 \mathrm{kGy}$ increased the transformation rate twice in the PB-1 homopolymer 110 , in the copolymer 9217 twenty times and in $8510-160$ times. The contribution of $198 \mathrm{kGy}$ irradiation was only marginal because the $r$ value increased from 0.03 to $0.02 \mathrm{~h}$.

Generally, the $r$ values decreased due to two factors: (1) irradiation dose and (2) mainly to the increased content of ethylene groups in copolymers.

Further measurements of transformation rate of some PB-1 polymer blends containing ethylene segments were intended to decide whether the increased transformation rate results only from the $-\mathrm{CH}_{2}-$ groups presence in contact with PB-1 molecular chains, or whether these groups should be part of copolymer chain. The results in Table III confirmed that the second assumption is valid.

From the data in Table III it is obvious that blending of PB-1 with LPE or paraffin can increase the transforma- tion rate but not in such an extent as in PB-1/ethylene copolymers. The blend preparation in melt or solution also affects the transformation rate.

TABLE II

Recrystallization II $\rightarrow$ I half time $r$ of PB-1 samples. Thermal history $195^{\circ} \mathrm{C} / 10 \min \rightarrow 25^{\circ} \mathrm{C}$.

\begin{tabular}{c|c|c}
\hline \hline Sample & Dose [kGy] & $r[\mathrm{~h}]$ \\
\hline 110 & 0 & 48 \\
& 99 & 36 \\
& 132 & 36 \\
& 165 & 36 \\
9217 & 198 & 24 \\
& 0 & 10 \\
& 66 & 0.7 \\
8640 & 99 & 0.7 \\
& 132 & 0.7 \\
& 198 & 0.5 \\
8340 & 0 & 10 \\
& 99 & 5 \\
& 132 & 5 \\
8510 & 198 & 1 \\
& 0 & 20 \\
& 66 & 12 \\
& 165 & 10 \\
& 198 & 50.03
\end{tabular}

TABLE III

Phase II $\rightarrow$ I recrystallization of PB- 1 sample 300 with some polymer additives. Thermal history $140{ }^{\circ} \mathrm{C} / 5 \min \rightarrow 25^{\circ} \mathrm{C}$.

\begin{tabular}{c|c|c|c|c}
\hline \hline Blend additive & {$[\%]$} & Blend preparation & {$[\% X]$} & $r[\mathrm{~h}]$ \\
\hline 0 & 0 & homopolymer & 78 & 48 \\
paraffin & 5 & melt blended & 65 & 23 \\
LPE & 5 & melt blended & 66 & 24 \\
branche PE & 5 & from xylene solution & 72 & $<24$ \\
iPP & 5 & from xylene solution & 83 & 48 \\
$85100 \mathrm{kGy}$ & 5 & from xylene solution & 78 & 48 \\
$8510198 \mathrm{kGy}$ & 5 & from xylene solution & 73 & 48 \\
paraffin & 5 & from xylene solution & 69 & 0.2 \\
LPE & 5 & from xylene solution & 66 & 0.2 \\
paraffin & 5 & from heptane solution & 63 & 6
\end{tabular}




\section{Conclusions}

Beta irradiation of PB-1 and its random ethylene copolymers results mainly in chain scission without chain cross-linking. Fresh melted samples are characterized after cooling to room temperature by the unstable crystal form II which spontaneously transforms in the stable form I. The transformation rate II $\rightarrow$ I at room temperature decreased from 2 days in the homopolymer and to minutes in copolymers due to ethylene content and irradiation dose. Simultaneously the beta irradiation decreases the PB-1 crystallinity and crystal size/perfection.

Some additives containing $-\mathrm{CH}_{2}-$ groups also increased the II $\rightarrow$ I transformation rate but one order of magnitude less than PB-1/polyethylene copolymers. Continuing research effort is aimed to achieve increasing II $\rightarrow$ I transformation rate even further. The beta irradiation effects on further polymer properties such as melting, crystal and spherulite morphology and mechanical properties will be described elsewhere.

\section{Acknowledgments}

Appreciation is expressed to Prof. P.H. Geil, for helpful comments. This research was financially supported by the Czech Ministry of Education, Youth and Sports in the $R \& D$ project under the title "Modelling and Control of Processing Procedures of Natural and Synthetic
Polymers", No. MSM 7088352102 and "CEBIA Tech", No. CZ.1.05/2.1.00/03.0089.

\section{References}

[1] M. Kaszonyiova, F. Rybnikar, P.H. Geil, J. Macromol. Sci. Phys. B 44, 377 (2005).

[2] C.D. Armeniades, E. Baer, J. Macromol. Sci., Phys. B 1, 309 (1967).

[3] A. Marigo, C. Marega, G. Cecchin, G. Collina, G. Ferrara, Eur. Polym J. 36, 131 (2000).

[4] R.S. Lehrle, C.S. Pattenden, Polym. Degrad. Stabil. 62, 211 (1988).

[5] J.P. Luongo, R. Salovey, J. Polym. Sci. 4, 997 (1966).

[6] M. Kaszonyiova, F. Rybnikar, L. Lapcik, D. Manas, J. Macromol. Sci. B, Phys. 51, 926 (2012).

[7] ČSN EN ISO 1133, Plasty - Stanovení hmotnostního (MFR) a objemového (MVR) indexu toku taveniny termoplastů, Český normalizační institut, Praha 2006.

[8] P. Scherrer, Bestimmung der Grosse und der inneren Struktur von Kolloidteilchen mittels Rontgenstrahlen (1918) in: X-ray Diffraction Methods in Polymer Science, Ed. L.E. Alexander, Wiley-Interscience, New York 1969, p. 582. 